\title{
EREBEA
}

Revista de Humanidades

y Ciencias Sociales

NúM. 7 (2017), pp. 225-252

ISSN: 0214-0691

\section{EL ARS MORIENDI: ¿UN MANUAL DEL BUEN MORIR?}

\section{Daniel Añua Tejedor \\ University of the Basque Country, Euskal Herriko Unibertsitatea}

RESUMEN

El siguiente artículo pretende dilucidar la conveniencia o desacomodo del uso del Ars moriendi del siglo XV para alcanzar una buena muerte en los umbrales de un fallecimiento. Con este fin, comenzaremos describiendo la vivencia atemporal que todo moribundo atraviesa al enfrentarse a su propia muerte, siempre y cuando se produzca de manera consciente. En esa descripción incluiremos las necesidades y esperanzas que configuran dicha vivencia. Posteriormente analizaremos las características y uso de dicha Ars; y a partir de ahí, su idoneidad para cubrir las necesidades y esperanzas descritas, que de manera involuntaria y espontánea, brotan inexorablemente en las postrimerías de la vida.

\section{Palabras Clave}

Ars moriendi; postrimerías; necesidades del moribundo; esperanzas del moribundo; buena muerte; mala muerte.

Fecha de recepción: 03 del 08 de 2017 Fecha de aceptación: 04 del 11 de 2017
ABSTRACT

The following article seeks to clarify conveniences or inadequacies of the use of the fifteenth-century Ars moriendi to reach a good death at the end of life. To this end, we will begin by describing the timeless experience that every dying person goes through in facing his own death, as long as it occurs consciously. In that description we will include the needs and the hopes that make up this experience. Subsequently, we will analyze the characteristics and the use of the Ars. From there on, we will examine its suitability to cover the needs and hopes described which arise inexorably in the later moments of life in an involuntary and spontaneous way.

\section{KEYwords}

Ars moriendi; last years; needs of the dying; hopes of the dying; good death; bad death. 



\section{INTRODUCCIÓN}

El siguiente artículo pretende dilucidar la conveniencia o desacomodo del uso del Ars moriendi del siglo XV para alcanzar una buena muerte cuando la vida llega a su término. Con este fin, comenzaremos describiendo la vivencia atemporal que todo moribundo atraviesa al enfrentarse a su propia muerte, siempre y cuando se produzca de manera consciente. En esa descripción incluiremos las necesidades y esperanzas que configuran dicha vivencia. Posteriormente analizaremos las características y uso de dicha Ars; y a partir de ahí, su idoneidad para cubrir las necesidades y esperanzas descritas, que de manera involuntaria y espontánea, brotan inexorablemente en las postrimerías de la vida.

\section{EL BUEN MORIR: UNA REALIDAD ATEMPORAL}

1.1. El moribundo y su vivencia

Para hacer una descripción de las necesidades del ser humano en el umbral de su propia muerte, me he basado en varios autores que han escrito profusamente sobre el tema y en aquellos que, en la actualidad, son referentes en los cuidados paliativos. Elisabeth Kübler-Ross describe el momento de morir del siguiente modo:

Esta experiencia es general, independiente del hecho de que se sea aborigen de Australia, hindú, musulmán, creyente o ateo. Es independiente también de la edad o del nivel socio-económico, puesto que se trata de un acontecimiento puramente humano, de la misma manera que lo es el proceso natural de un nacimiento ${ }^{1}$.

A lo largo de la historia, el contexto que ha rodeado los fallecimientos no ha dejado de modificarse hasta llegar a un presente en el que los adelantos técnicos y el modo de vida han configurado la visión que tenemos del morir y han modificado los comportamientos para afrontar el hecho de que un allegado se encuentre cerca de su fallecimiento. 
A este respecto, Kübler-Ross describe así la situación actual:

Creo que hay muchas razones por la que no se afronta la muerte con tranquilidad. Uno de los hechos más importantes es que, hoy en día, morir es más horrible en muchos aspectos, [...], es algo solitario, mecánico y deshumanizado; [...] El morir se convierte en algo solitario e impersonal porque a menudo el paciente es arrebatado de su ambiente familiar y llevado a toda prisa a una sala de urgencia. [...] El paciente hoy sufre más, no físicamente quizá, pero sí emocionalmente. Y sus necesidades no han cambiado a lo largo de los siglos, sólo nuestra capacidad para satisfacerlas ${ }^{2}$.

En la misma línea, Jorge L. Tizón hace una descripción bastante dramática, pero realista, de la situación generada por nuestra sociedad en su conjunto:

Morir hoy en día en una urbe occidental es, en más del $80 \%$ de las ocasiones, morir intubado, sin poderse comunicar, anestesiado y sedado, inconsciente, alimentado artificialmente, perfundido... Y, sobre todo, a menudo es morir (bastante) solo, en el hospital, marginado de todo lo que hasta entonces ha supuesto la vida para ese moribundo que podríamos ser nosotros mismos ${ }^{3}$.

A pesar de la evolución diacrónica que ha experimentado el marco social, religioso, cultural y familiar que ha circundado durante siglos los fallecimientos, la vivencia personal experimentada por el moribundo en los últimos momentos de su vida no ha evolucionado de la misma manera; antes bien, ha permaneciendo estable siempre y cuando el grado de consciencia se hubiese mantenido. Por esa razón, es necesario identificar qué necesidades y esperanzas precisa cubrir el moribundo en los umbrales de su fallecimiento para alcanzar una buena muerte. Del mismo modo, es preciso identificar las actitudes y las acciones que su entorno más inmediato ha de evitar para librarle de una mala muerte.

\subsection{Buena muerte versus mala muerte}

Cuando nos aproximamos a nuestra propia muerte, como relatan muchos moribundos, atravesamos cinco fases: negación, ira, negociación, depresión y aceptación $n^{4}$. Si a lo largo de estas fases se encuentran acompañados por un ser que

2 Kübler-Ross, Sobre la muerte..., pp. 21 y 24.

3 Jorge L. Tizón, Pérdida, pena, duelo. Vivencias, investigación y asistencia. Barcelona: Paidós, 2004, p. 37.

4 Kübler-Ross, Sobre la muerte..., pp. 47; Wilson Astudillo Alarcón, A. García de Acilu, C. Mendinueta y C. Arrieta, Estrategias para la atención integral en la terminalidad. San Sebastián: 
les ama, pueden alcanzar con más éxito la fase de aceptación ${ }^{5}$. En el momento de enfrentarnos con nuestra propia muerte, el miedo y la ansiedad ante lo que va a acontecernos están presentes, siendo esta última la más frecuente y la más investigada $^{6}$. Toda nuestra vida parece rebobinarse una y otra vez ante nosotros cuando vamos a fallecer y recordamos: "con obstinada repetición, los proyectos inconclusos, los sueños abortados, los traspiés de toda índole, las amistades descuidadas, los amores traicionados"

Muchos son los autores que han intentado definir las características de una buena muerte a partir de las necesidades observadas por ellos y de las expresadas por los propios moribundos. Dichas necesidades aparecen enumeradas en un artículo de Smith y Maher ${ }^{8}$ del que se hacen eco autores como J. Cavrin y C.R. Chapman? Para conocer dichas necesidades, recojo la tabla aparecida en el año 2005 en la $R e-$ vista de Estudios Médico Humanísticos: Ars Medica, fruto de una encuesta realizada a Directores de Unidades de Cuidados Paliativos en Estado Unidos. En ella se recoge las necesidades señaladas por Smith y Maher, pero ordenándolas porcentualmente según la importancia que les otorgan las personas atendidas en dichas unidades:

Tabla 1: Requisitos para tener una muerte apacible:

\begin{tabular}{|l|l|}
\hline Tener cerca a alguien significativo & $97,4 \%$ \\
\hline Escuchar la verdad & $96,0 \%$ \\
\hline Tener control sobre su cuidado & $92,4 \%$ \\
\hline Dialogar sobre hechos prácticos/muerte & $92,1 \%$ \\
\hline Participar en expresiones afectivas & $92,0 \%$ \\
\hline Cuidar su apariencia y aseo & $89,6 \%$ \\
\hline Recordar su pasado & $87,5 \%$ \\
\hline Disfrutar del humor & $83,6 \%$ \\
\hline Hablar de asuntos espirituales & $79,1 \%$ \\
\hline
\end{tabular}

Sociedad J Vasca de Cuidados Paliativos, 1999, pp. 70-73.

5 Kübler-Ross, Sobre la muerte..., pp. 47.

6 Lori Anne Thompson Hansen, La ansiedad ante la muerte y el propósito en la vida en fin de vida. Tesis doctoral, Universidad de Deusto, 1997, p. 17.

7 Iosu Cabodevilla, La espiritualidad en el final de la vida. Bilbao: Desclée De Brouwer, 2007, pp. 74-75.

8 Douglas Smith and Michael Forrest Maher, "Achieving a healthy death: The dying person's attitudinal contributions", en Hosp J, no 9, (1993), pp. 21-23.

9 J. Gavrin and C. R. Chapman, "Clinical Management of Dying Patients", en Western Journal of Medicine, no 163, no 3 (1995), p. 271. 
De entre todas ellas, destaco la relevancia de tener cerca a alguien significativo, a un familiar querido, a la persona con la que hemos compartido la vida (97,4\%).

La importancia que se da a la presencia a nuestro alrededor de las personas que amamos ${ }^{10}$, a la necesidad de no morir solos y separados de ellas "without warm human contact" ${ }^{11}$ (Gavrin and Chapman), a ser tocados y acariciados en silencio $^{12}$, a reconciliarnos con los demás ${ }^{13}$ y a expresar tanto sentimientos reprimidos como todo aquello que necesitamos expresar ${ }^{14}$ resulta clave para alcanzar la fase de aceptación. Tendremos más posibilidades de lograr este objetivo si mantenemos el máximo control posible en la toma de decisiones, tanto de aquellas que nos afectan directamente como de aquellas que atañen a nuestro entorno afectivo, llegando así a la fase de aceptación en la que poder "seguir viviendo el presente con una sensación de paz interior" ${ }^{15}$ por haber sido protagonistas hasta el final ${ }^{16}$. De esta manera se evitaría la repetida queja de los moribundos de que se hable de ellos, pero no con ellos ${ }^{17}$, lo que David Sudnow denominó "muerte social": "that point at which a patient is treated essentially as a corpse, though perhaps still 'clinically' and 'biologically' alive"18.

En este trance final, el moribundo necesita que se le ofrezca esperanza, no de curación o de evitación de la inevitable muerte, valga la redundancia, sino la esperanza de que aliviaremos su soledad a través del acompañamiento y su malestar a través del control de síntomas ${ }^{19}$.

10 Ramón Bayés, Psicología del sufrimiento y de la muerte. Barcelona: Ediciones Martínez Roca, 200I, p. 76; Committee on Care at the End of Life, Division of Health Care Services, Institute of Medicine, Approaching dead: Improving care at the end of life, Marilyn J. Field and Christine K. Cassel (eds.). Washington, D.C.: National Academy Press, 1997, p. 24; Cabodevilla, La espiritualidad..., p. 77.

11 Gavrin and Chapman, "Clinical Management..., p. 270.

12 Kübler-Ross, Sobre la muerte..., pp. 148-149; Wilson Astudillo Alarcón y Carmen Mendinueta, "Necesidades de los enfermos en el final de la vida", en Ars Médica, no 11, 2005, p. 141.

13 Committee on Care ..., Approaching dead..., p. 24; Ira R. Byock, "Why Do We Make Dying So Miserable?", en The Washington Post, no 22 (January), $1991 \mathrm{~b}$.

14 Cabodevilla, La espiritualidad..., pp. 76-77.

15 Bayés, Psicología del sufrimiento..., p. 28.

16 Smith \& Maher, "Achieving a healthy death; Bayés, Psicología del sufrimiento..., p. 76; Gavrin and Chapman, "Clinical Management..., p. 27I; Donald S. Swenson, Society, Spirituality, and the Sacred: A Social Scientific introduction. Toronto: University of Toronto Press incorporated, 2009, p. 46; Pilar Arranz, José Barbero, Pilar Barreto y Ramón Bayés, Intervención emocional en cuidados paliativos. Barcelona: Ariel, 2003, p. 38; Carmelita McNeil, "A good death", en Journal of Palliative Care, vol. 14, no 1 (1998), p. 5.

17 Bayés, Psicología del sufrimiento..., p. I47.

18 David Sudnow, Passing On: The Social Organization of Dying. New Jersey: Prentice-Hall, 1967, p. 74.

19 Bayés, Psicología del sufrimiento..., p. 74. 
En cuidados paliativos, a medida que la enfermedad progresa, a los pacientes se les pueden facilitar y pueden expresar diferentes "pequeñas" y realistas esperanzas [...]: esperanza de que los medicamentos aliviarán el dolor, que el sueño de la próxima noche será tranquilo, que vendrá un amigo a visitarle al día siguiente, etc. Aun cuando no exista esperanza de curación, el enfermo debe, y en muchas ocasiones puede, mantener estas otras formas de esperanza. [...] ¡No se puede seguir viviendo sin alguna esperanza! ${ }^{20}$.

Esas esperanzas también incluyen lo que en cuidados paliativos se denomina "the five things": poder pedir perdón, poder perdonar, poder dar las gracias, poder decir: te quiero y, finalmente, poder decir adiós. Compartir estos sentimientos con aquellos a quienes queremos, proporciona "a sense of completion and peace"21; incluso el mero tacto de aquellos a quienes amamos puede ser "un antídoto contra el temor y la ansiedad" en esos momentos ${ }^{22}$.

Del mismo modo que podemos enumerar las características de una buena muerte, podemos, en contraposición, señalar qué características se deberían evitar para eludir una mala muerte.

The Committee on Care at the End of Life considera que una mala muerte se caracteriza $\operatorname{por}^{23}$ :

- A needless suffering, dishonoring of patient or family wishes or values

- A sense among participants or observers that norms of decency have been offended

- Resulting from or accompanied by neglect, violence, or unwanted and senseless medical treatments

Esta pérdida de control involuntaria sobre nuestra propia vida siempre lleva parejo una situación de falta de respeto. Para Arranz, Barbero, Barreto y Bayés las intervenciones paternalistas propias de nuestra cultura responden a la necesidad de ejercer dicho control; por ello, proponen la evolución desde dichas intervenciones hacia aquellas que ayuden al moribundo a tomar las decisiones que considere apropiadas sin dejar el gobierno de su vida en manos de otros. Para lograrlo, las personas que rodeen al moribundo necesitan haber aprendido:

20 Ibidem, pp. $74-75$.

21 Ira R. Byock, Dying Well: The Prospect for Growth at the End of Life. New York: Riverhead Books, 1997a, p. 140.

22 Wilson Astudillo Alarcón y Carmen Mendinueta, "Necesidades de los enfermos en el final de la vida", en Ars Medica no 11, (2005), p. 141.

23 Committee on Care ..., Approaching dead..., p. 24. 
[...] a manejar y confrontar sus propios miedos, la angustia asociada a ellos, los sentimientos de impotencia y frustración generados por los deseos imposibles, las creencias erróneas, las reacciones impulsivas o los comportamientos de evitación [...] Es preciso recordar que las personas que dan consejos directamente - en lugar de preguntar, explorar el problema y escuchar- aumentan la incertidumbre y la ansiedad del paciente, lo cual es precisamente lo opuesto a uno de los objetivos terapéuticos fundamentales que se intentan alcanzar ${ }^{24}$.

Por tanto habría que evitar también la distanasia o encarnizamiento terapéutico así como cualquier otra falta de respeto hacia el moribundo y sus familiares. Si la distanasia es "la obcecación por salvar la vida del enfermo utilizando todo el armamento terapéutico de que se dispone, aunque las posibilidades de conseguir salvar al enfermo sean casi nulas y se esté manipulando el cuerpo del enfermo hasta límites a veces increíbles y no deseados al inicio del tratamiento" 25 , podemos hablar de otro tipo de distanasia que denominaremos encarnizamiento religioso. Dicho encarnizamiento representa la obcecación por salvar el alma del moribundo utilizando todo el armamento de que se dispone y obviando los deseos de éste. Se llevaría a cabo sin su consentimiento, aunque se alegase la mejor de las intenciones. De hecho dentro de los riesgos para no lograr una buena muerte se citan los dos siguientes:

- Exposing some patients and families to feelings of guilt and anger because conflicts were not resolved or reconciliations achieved or spiritual serenity reached.

- Reflecting values of the dominant culture that are not shared by all and it may induce some naive caregivers to try subtly or not so subtly to impose their values on dying patients and families ${ }^{26}$.

Este segundo riesgo podría englobar actitudes relacionadas con las creencias religiosas de la sociedad, de la Iglesia o del entorno, así como otras creencias perjudiciales que, aunque no sean de carácter religioso, están socialmente extendidas.

1.3. La religiosidad en las postrimerías de la vida

La relevancia que la actitud religiosa tiene a la hora de enfrentarnos con el miedo y con la ansiedad ante la muerte propia ha sido ampliamente estudiada en las últimas décadas.

24 Arranz, et al., Intervención emocional..., p. 44.

25 Bayés, Psicología del sufrimiento..., p. 143.

26 Committee on Care ..., Approaching dead..., p. 24. 
En 1950, Gordon Allport definió lo que era la religiosidad madura e inmadura $^{27}$. A partir de sus definiciones, en 1967, creó junto con J. Michael Ross la Escala de Orientación Religiosa [ROS]. Tal escala distinguía, desde el punto de vista de la motivación, entre religiosidad extrínseca [ER] o inmadura y religiosidad intrínseca [IR] o madura. Para ellos, la persona motivada extrínsecamente usa la religión para sus propios fines, mientras que la motivada intrínsecamente vive su religión. Los valores extrínsecos son siempre “instrumental and utilitarian”. Las personas con motivación extrínseca encuentran la religión útil en muchos sentidos tales como proporcionar seguridad y consuelo, sociabilidad y distracción, status y auto-justificación. Este tipo de religiosidad o credo adoptado o bien se mantiene a la ligera o bien se moldea selectivamente para satisfacer las necesidades más primarias ${ }^{28}$.

Para las personas con motivación intrínseca, su "master value" se encuentra en la religión, supeditando otras necesidades que armonizan con dichas creencias. Las personas que adoptan este tipo de religiosidad o credo se esfuerzan por interiorizarlo y seguirlo en su totalidad.

Los autores también consideraban que la mayoría de la gente se encontraba en un continuo entre estos dos polos sin que hubiesen encontrado casos puros. Así mismo consideran que no es tan importante saber si una persona es religiosa o no como saber el papel que juega la religión en sus vidas ${ }^{29}$.

Posteriormente, M. J. Donahue ${ }^{30}$ señaló que el miedo a la muerte se relaciona negativamente con la religiosidad intrínseca y positivamente con la religiosidad extrínseca afirmación corroborada por Powell \& Thorson ${ }^{31}$ y posteriormente por Cohen, Pierce, Chambers, Meade, Gorvine y Koening ${ }^{32}$. De manera relevante, la investigación realizada por Nelson and Cantrell ${ }^{33}$, recogida por Powell \& Thorson en su artículo ${ }^{34}$, nos indica que el menor grado de ansiedad ante la muerte, no

27 Gordon W. Allport, The Individual and His Religion: A Psychological Interpretation. London: Constable, 1950, pp. 61-65.

28 Gordon W. Allport and J. Michael Ross, "Personal religious orientation and prejudice", en Journal of Personality and Social Psychology, vol. 5, no 4 (1967), p. 434.

29 Ibidem, p. 434.

30 M. J. Donahue, "Intrinsic and extrinsic religiousness: Review and meta-analysis, en Journal of Personality and Social Psychology, vol. 48, no 2 (1985), p. 407.

31 F. C. Powell \& James A. Thorson, "Constructions of death among those high in intrinsic religious motivation: A factor-analytic study”, en Death Studies, vol. 15, no 2 (1991a), p. 131.

32 Adam B. Cohen, John D. Pierce Jr., Jacqueline Chambers, Rachel Meade, Benjamin J. Gorvine and Harold G. Koenig, "Intrinsic and extrinsic religiosity, belief in the afterlife, death anxiety, and life satisfaction in young Catholics and Protestants, en Journal of Research in Personality, $\mathrm{n}^{\circ} 39$, (2005), pp. 314-315.

33 L. D. Nelson and C. H. Cantrell, "Religiosity and death anxiety: A multidimensional analysis", en Review of Religious Research, vol. 21, no 2 (1980), p. 154.

34 F. C. Powell \& James A. Thorson, "Life, Death, and Life after Death: Meanings of the Relationship between Death Anxiety and Religion”, en Journal of Religious Gerontology, vol. 8, nº, 
sólo se da en creyentes intrínsecos, sino también en los no-creyentes. Para Powell $\&$ Thorson, las personas con alta religiosidad intrínseca han resuelto su problema existencial, pero añaden que la creencia en una vida después de la muerte modera la ansiedad tanto de las personas con religiosidad intrínseca como extrínseca, siendo este hecho más relevante para ellos que el tipo de religiosidad practicada ${ }^{35}$. Igualmente Cohen y sus colegas consideran que "belief in an afterlife could provide an especially effective buffer against fear of death and thereby promote well-being. This is an important research question as death anxiety could pose a significant threat to people's sense of well-being" 36 .

Recopilando las teorías expuestas hasta el año 2009, Donald S. Swenson nos recuerda la combinación que Spilka, Hood y Gorsuch hicieron en 1985 de los aspectos motivacionales de Allport y Ross de 1967 (religiosidad intrínseca y extrínseca) y de los aspectos cognitivos de Allen y Spilka del mismo año (committed faith y consensual religion) creando a partir de estos cuatro aspectos las categorías de intrinsic-committed y extrinsic-consensual. Swenson señala que para Spilka, Hood y Gorsuch la espiritualidad intrinsic-committed sería una espiritualidad abierta, cordial, abstracta, con capacidad de discernir y relevante desde el punto de vista personal. Mientras que la espiritualidad extrinsic-consensual sería restrictiva, aislante, concreta, simplista e irrelevante desde el punto de vista personal, ya que tiende a carecer de fundamentación en el conocimiento ${ }^{37}$. Los primeros ven la muerte de manera positiva, mientras que los segundos de manera negativa ${ }^{38}$.

\section{Descripción de las Artes moriendi}

\subsection{Contexto eclesial de aparición}

El texto oficial de las Artes moriendi se sancionó en el Concilio Ecuménico de Constanza celebrado entre el 5 de noviembre de 1414 y el 22 de abril de $1418^{39}$. Dicho concilio puso punto final al gran cisma de Occidente (1378-1418) con la elección del Cardenal Colonna como único papa de la Cristiandad con el nombre de Martín V el 11 de octubre de 1417. Para llevar a cabo tal elección, fue necesaria la deposición y excomunión de Benedicto XIII, conocido como el papa Luna; la abdicación del predecesor de Martín V, el papa Gregorio XII, y la del papa Juan XXIII, tercer papa existente en ese momento y elegido en el Concilio de Pisa. El Concilio Ecuménico de Constanza decidió servirse de las recién sancionadas Artes

1 (1991b), p. 43.

35 Ibidem, pp. 52 y 54.

36 Cohen, et al., "Intrinsic and extrinsic religiosity..., p. 309.

37 Swenson, Society, Spirituality..., p. 45.

38 Ibidem, p. 46.

39 Ashby Kinch, Imago Mortis. Mediating Images of Death in Late Medieval Culture. LeidenBoston: Brill, 2013, p. 35. 
para la predicación relativa al final de la vida ${ }^{40}$. El miedo a morir fuera de la Iglesia, en la que Dios había delegado su poder, contribuyó a reforzar y recuperar el lugar de superioridad de una estructura fuertemente sacudida por el gran cisma ${ }^{41}$.

Según González, Saquero y Caerols, uno de los participantes más activo en el Concilio de Constanza fue Jean Gerson (1363-1429). De entre sus 434 obras, destaca un pequeño texto en francés titulado La science de bien mourir ou la médecine de l'âme que fue traducido al latín por él mismo junto con otras dos obras suyas tituladas Miroir de l'âme y Examen de conscience. Estas tres obras conformarán el Opusculum tripertitum, libro muy conocido en toda Europa y, especialmente, en Francia. De scientia mortis es el título latino que La science de bien mourir ou la médecine de l'âme adopta en el Opusculum tripertitum como tercera y última parte del mismo y constituye el arquetipo o punto de partida del que nacieron las dos redacciones latinas de las Artes moriendi: Tractatus artis bene moriendi, o versión amplia, y Ars moriendi, o versión corta ${ }^{42}$.

La versión corta del Ars moriendi fue traducida al alemán, holandés, francés, castellano y catalán; mientras que la versión larga no sólo fue traducida a esas mismas lenguas sino también al inglés y al italiano ${ }^{43}$, propiciando su gran difusión y su comprensión tanto en el ámbito de las clases más altas, como en el seno de un público más amplio ${ }^{44}$.

Su amplia difusión, tanto en sus redacciones originales como en sus traducciones a las distintas lenguas vulgares europeas, no habría sido posible sin la difusión $\mathrm{y}$ arraigo de la creencia en el juicio particular ${ }^{45}$ y sin la intervención de las órdenes mendicantes de los dominicos y los franciscanos ${ }^{46}$.

\subsection{Estructura de las dos versiones}

A pesar de su fecha de sanción, este texto, según indica Haindl ${ }^{47}$, recogía una tradición que se remonta a los orígenes de la Iglesia, ya que, como se documenta en el Concilio de Nicea de 325, la muerte se consideraba desde entonces "el mo-

40 Tomás González Rolán, Pilar Saquero Suárez-Somonte y José Joaquín Caerols Pérez, Ars moriendi: el "Ars moriendi" en sus versiones latina, castellana y catalana: introducción, edición crítica y estudio. Madrid: Ediciones Clásicas, 2008, p. 22.

41 Florence Bayard, L'art du bien mourir au XV siècle. Paris: Presses de L'Université de Paris-Sorbonne, 1999, p. 120.

42 González Rolán, et al., Ars moriendi..., p. 22.

43 Ibidem, p. 41.

44 Ibidem, p. 48.

45 Ibidem, p. 42.

46 Ibidem, pp. 22-23.

47 Ana Luisa Haindl, "La muerte en la Edad Media", en Revista electrónica. Historias del Orbis Terrarum, no 1 (2009), p. 153. Puesto en línea en 2009. Disponible en https://historiasdelorbisterrarum.files.wordpress.com/2008/11/ana-luisa-haindl-muerte-en-la-edad-media.pdf. Consultado en 15/4/2016. 
mento clave para la salvación de las almas" aunque con características diferentes según los distintos periodos.

Como indica Emilio Blanco ${ }^{48}$, la versión larga denominada Tractatus artis bene moriendi o Speculum artis bene moriendi está etiquetada con las siglas CP ya que comienza siempre con Cum de presentis (exilii miseria mortis transitus) mientras que la versión corta denominada propiamente Ars moriendi, está etiquetada como QS, cuya primeras palabras son Quamuis Secundum (Philosophum tercio Ethicorum).

La versión larga se divide en seis partes:

1. Una introducción general sobre el arte de morir

2. Las tentaciones del moribundo

3. Las preguntas que se le formularán

4. Las oraciones que le conviene rezar

5. Cómo deben comportarse los que le rodean

6. Los rezos apropiados para estos últimos

Sin embargo, la versión corta o QS recoge únicamente la segunda parte de la versión CP precedida de una introducción y seguida de una conclusión.

La versión larga se conserva manuscrita y sin grabados, a diferencia de la versión corta que está impresa e ilustrada con once grabados correspondientes a las cinco tentaciones del diablo y a otras tantas inspiraciones del ángel. A estos diez grabados se añade uno más que representa la buena muerte del agonizante ${ }^{49}$. A través de estas Artes, la Iglesia consideró a comienzos del siglo XV que "el aprendizaje de la doctrina espiritual podía alcanzar tanto a los que sabían leer como a lo que desconocían las letras, y que la solución se encontraba en la unión de texto literario y representaciones gráficas en un mismo libro". El Ars moriendi, o versión corta, logra una conexión perfecta entre texto e imágenes; texto que trata de enseñar a bien morir defendiéndose de las tentaciones del diablo para alcanzar el paraíso, e imágenes que potencian dicho texto, pero que, por sí solas, también hacían visible el contenido del mismo ${ }^{50}$.

De la versión corta contamos con dos traducciones, una en castellano y otra en catalán. La primera está editada tipográficamente en Zaragoza, por Pablo Hurus y Juan Planck (1479-1483) ${ }^{51}$, mientras que de la segunda contamos con tres

48 Emilio Blanco, "Artes de bien morir: para vivir mejor", en J. M. Lucía (ed.): Actas del VI Congreso Internacional de la Asociación Hispánica de Literatura Medieval, vol. I. Alcalá: Servicio de Publicaciones Universidad de Alcalá, 1997, p. 301.

49 González Rolán, et al., Ars moriendi..., p. 61.

50 Ibidem, p. 25.

51 De esta edición sólo se conserva el ejemplar que se encuentra en la Biblioteca del Monasterio de El Escorial (signatura 32-V-19), editada por Francisco Gago Jover. Su edición aparece recogida por Tomás González Rolán, Pilar Saquero Suárez-Somonte y José Joaquín Caerols Pérez junto con 
ediciones: la edición de Zaragoza, por Juan Hurus hacia 1488-1493, la edición de Valencia, en 1497, y la edición de Barcelona, por Gabriel Pou en $1507^{52}$.

Si atendemos a la enumeración de las seis partes en que se divide la versión larga, podemos intuir el establecimiento de una serie de indicaciones que determinarán tanto los comportamientos del moribundo como de sus dolientes. Sin embargo, me centraré en la versión corta en la que también se aprecia con claridad dichas pautas.

\subsection{Condiciones para su puesta en práctica}

Según Ana Isabel Haindl53 ${ }^{33}$ el Ars moriendi buscaba crear consciencia acerca de la propia muerte subrayando el carácter religioso a diferencia de la Dança de la muerte que subrayaba el carácter satírico-profano. Sin embargo, ambas "se inscriben dentro de la misma función pedagógica: procurar una buena muerte, tomando consciencia de la mortalidad de todo ser humano y viviendo una buena vida".

Aunque el Ars moriendi pretendía ayudar al moribundo en la agonía, es difícil que, en tal trance, el moribundo tuviera el ánimo y las condiciones físicas necesarias para su lectura. Por tanto, según explica Blanco ${ }^{54}$, estas obras deberían enmarcarse en un proceso de evangelización para seglares poco instruidos y de educación para clérigos presentes junto al lecho de los moribundos. Esto explicaría, a su juicio, los grabados con los cuales el sacerdote instruiría al moribundo a cerca de las cinco tentaciones que tendría que afrontar, siempre y cuando, mantuviera el nivel de consciencia suficiente. En cuanto a la parte textual, algunos de estos manuales recogen en su encabezamiento la recomendación de una lectura de pasajes concretos y no de todo el texto, atendiendo de este modo a la gravedad del enfermo. Aún así, Blanco no descarta su lectura durante las etapas de vida saludable del creyente como forma de preparación para el momento de su muerte.

Considero importante señalar la reflexión que hace Johan Huizinga para explicar su gran difusión ${ }^{55}$ : "Parece como si el hombre ya no supiera morir". Para llegar a este punto, se ha producido una evolución desde las serenas muertes propias del antiguo ritual del mort gisant, hasta alcanzar la realidad expuesta por Huizinga. Todas aquellas necesidades cubiertas de un modo proactivo y participativo del antiguo ritual irán dando paso a una pérdida progresiva del protagonismo tanto del moribundo como de sus dolientes. ${ }^{56}$

la versión latina y catalana.

52 González Rolán, et al., Ars moriendi..., pp. 41-42.

53 Ana Luisa Haindl, "La Danza de la Muerte", 2011, p. 16. Disponible en http://www.edadmedia.cl/docs/danza_de_la_muerte.pdf. Consultado en 15/04/2016.

54 Blanco, "Artes de bien morir..., pp. 301-302.

55 Johan Huizinga, El otoño de la Edad Media. Madrid: Alianza ensayo, 2001, p. 211.

56 Para más información, véase Philippe Ariès, Historia de la muerte en Occidente: desde la Edad Media hasta nuestros dias, Barcelona, El Acantilado, 2000 y El hombre ante la muerte, Madrid, Tau- 
Las prerrogativas eclesiales que el creyente debía obedecer para preparase antes de la muerte, mencionadas en los manuales del buen morir, proponían "una serie de fórmulas y oraciones de última hora para reservarse automáticamente una entrada en el reino de los cielos" 57 . Una vez que el creyente se encontraba en las postrimerías de su vida, debía afrontar las tentaciones con una batería de fórmulas, oraciones y gestos descritos por Lawrance en el siguiente fragmento:

Contra tales peligros el agonizante debía precaverse clavando los ojos en el Crucifijo, rezando sin cesar las debidas oraciones, apretando los dientes para no dejar escapar ningún suspiro o murmullo de dolor, y agarrando cuanto podía el cirio encendido que le ponían entre manos ${ }^{58}$.

El moribundo debía centrarse en dichas fórmulas y oraciones abandonando cualquier pensamiento ajeno a ellas con todas sus fuerzas y toda su consciencia como recoge el capítulo XI de la versión castellana del Ars moriendi ${ }^{59}$ :

Si el que está en la agonía e artículo de la muerte pudiera fablar e usar de la razón, trabaje por ocuparse en oraciones, primeramente llamando a Dios e suplicándolo que tenga por bien de rescibir a él en su gloria, por la su sanctíssima e marabillosa misericordia e por la virtud de su Passión. Segúndo, diligentemente invoque e llame a la Gloriosa e Sacratíssima Virgen Señora Santa María, suplicándola que sea su abogada e medianera. E dende, ruegue a todos los ángeles, e especialmente al ángel deputado por su guarda, e assí mesmo a todos los santos apóstoles, mártires, confessores e vírgines. Empero, más specialmente ruegue e se encomiende a aquellos santos o santas en los quales primero seyendo sano tenía devoción e los honrrava o servía e amava, cuyas imágines, con la imagen del crucificio, le deven ser representadas (Cap. XI).

rus, 2011. También Daniel Añua-Tejedor, El proceso de deshumanización del morir en la literatura hispánica medieval (2013-2015), Tesis doctoral, Universidad del País Vasco/EHU. Disponible en http://hdl.handle.net/10810/16563

57 Blanco, "Artes de bien morir..., p. 304.

58 Jeremy Lawrence, "La muerte y el morir en las letras ibéricas al fin de la Edad Media", en Aengus Ward (coord.), Actas del XII Congreso de la Asociación Internacional de Hispanistas, vol. I. Birmingham: University of Birmingham, 1995, p. 12.

59 De ahora en adelante cito por la edición de Tomás González Rolán, Pilar Saquero SuárezSomonte y José Joaquín Caerols Pérez, Ars moriendi: el "Ars moriendi" en sus versiones latina, castellana y catalana: introducción, edición crítica y estudio. Madrid: Ediciones Clásicas, 2008. 
El moribundo debía buscar su salvación a través de las siguientes cinco amonestaciones que se le debían realizar y que recoge el proemio del Ars moriendi:

Primeramente, que crea así como buen cristiano los artículos de la fe, segund que la Santa Madre Iglesia los tiene e cree. Segundo, que sea alegre porque muere en la fe de Nuestro Señor Ihesu Cristo e en la obediencia e unidad de su Santa Iglesia. Tercero, que proponga en su coraçón de emendar su vida, si más viviere, e de non pecar más, ni ofender a Dios ni a sus próximos. Quarto, que perdone por amor de Dios a los que le han offendido e pida perdón de aquellos que él ha injuiriado. Quinto, que torne las cosas agenas. Sesto, que conosca e crea que Ihesu Cristo murió por salvar a nosotros e por él, e que de otra manera non puede ser salvo, sino por mérito de la su Santa Passión, por lo qual faga gracias a Dios en quanto puede. E si a estas cosas respondiere de buen coraçón, señal es que es del número de los que se han de salvar (Prohemio).

La necesidad de solucionar, en la medida de lo posible y junto a sus seres queridos, cuestiones de índole práctico, que no solo afectan al dinero, no está bien vistas en el Ars moriendi:

La final temptación de que el diablo tiempta en el artículo de la muerte es de avaricia, de la qual más usa contra los seglares e carnales, que es la mucha ocupación de las cosas temporales et exteriores; como cerca de las mujeres et fijos, parientes e amigos carnales, e cerca de las riqueças e otras cosas que en su vida amaron (Cap. IX).

Así lo corrobora el capítulo X cuando explica la necesidad de abandonar dichas preocupaciones para alcanzar la salvación:

¡O ombre, aparta tus orejas de las falsas e mortiferas sugestiones e consejos del diablo, con que te piesa e procura engañar e cegar! E ante, todas cosas olvida e pospone todos los bienes e cosas temporales del todo, cuya memoria, por cierto, ninguan cosa de salud te puede causar e dar, mas antes muy grand impedimento e estorvo de tu salud spiritual.

Sin olvidar que el amor a las cosas terrenales aparta de Dios:

[...] quando el enfermo se siente temptado de avaricia o del amor de las cosas terrenales, primero debe considerar cómo el desseo e amor de las cosas terrenales aparta de Dios, porque excluye a e quita el amor de Dios (Cap. X). 


\subsection{Evolución del Juicio y su concreción en el Ars}

Según Ariès ${ }^{60}$, el tiempo escatológico que existía entre la muerte de cada individuo y el juicio que iba a tener lugar al final de los tiempos desaparece con las Artes. Ya no acontecerá al final de los tiempos como sucedía hasta el siglo XII, ni tampoco inmediatamente después del óbito como en el XIII, sino en la mismísima habitación del moribundo, en torno a su lecho, adelantándose a su defunción. Tras este juicio no colectivo que cada persona habría de afrontar individualmente, el alma conocerá su suerte en un nuevo más allá que ha adoptado una división ternaria (cielo - purgatorio - infierno) a partir del siglo XIII.

Estos cambios en la concepción cristiana ya no permiten hablar de dos vidas y dos muertes, como sucedía hasta finales del siglo XII, sino de tres vidas:

- La vida terrenal

- La vida de la Gloria que disfrutará el alma, separada del cuerpo, tras la muerte física

- La vida eterna que, tras la Resurrección de la carne, disfrutará tanto el alma como el cuerpo

Del mismo modo, existirán tres muertes:

- La primera muerte o muerte física, común a toda la humanidad por el pecado original

- La segunda, la muerte del alma que acontece tras la aparición del nuevo juicio particular que tiene lugar en el momento del fallecimiento

- La tercera muerte que tiene lugar tras el Juicio Final y la Resurrección de la carne y que afecta por igual tanto al alma como al cuerpo $^{61}$.

Según González Rolán, Saquero Suárez-Somonte y Caerols Pérez, con las Artes moriendi no se pretendía provocar el miedo a la muerte primera o física sino a la segunda muerte, la muerte del alma, que de modo inexorable había de conducirle a la condenación eterna sin el debido arrepentimiento ${ }^{62}$. La gravedad de la muerte del alma superaba a la del cuerpo como podemos leer en el proemio del Ars moriendi donde se recoge una cita de san Agustín que los autores no han podido determinar:

60 Philippe Ariès, Historia de la muerte en Occidente: desde la Edad Media hasta nuestros días. Barcelona: El Acantilado, 2000, p. 48.

61 González Rolán, et al., Ars moriendi..., pp. 19-20.

62 Ibidem, p. 21. 
[...] la más espantable de las cosas terribles sea la muerte, empero, en ninguna manera se pude comparar a la muerte del ánima. Esto confirma Sant Augustín, que dize que: 'Mayor dapño es la perdición de una ánima que de mil cuerpos' (Prohemio).

La promoción del miedo a la segunda muerte transformó las vivencias de las agonías, provocando que se abandone el antiguo ritual del mort gisant en el que el moribundo, rodeado de sus amigos y parientes, disponía sus últimas voluntades. Con las Artes moriendi se produce una escalofriante variante: "La habitación ha sido invadida por seres sobrenaturales que se apiñan en la cabecera del yacente" suplantando a los allegados.

A un lado:

- La Trinidad

- La Virgen

- La corte celestial

Al otro:

- Satán

- El ejército de los demonios monstruosos

El cambio resultaba significativo: "la gran concentración que en los siglos XII y XIII tenía lugar al final de los tiempos se produce a partir de ahora, en el siglo $\mathrm{XV}$, en la habitación del enfermo" ${ }^{3}$. No hay que olvidar, como nos recuerda Ariès, que esta invasión no es visible a los ojos de los amigos y parientes, sólo puede ser vista por el moribundo. Además en este nuevo escenario se producen también otras modificaciones. Ya no estamos ante un juicio, sino ante una lucha. Dios deja de ser juez para transformarse en árbitro. Esta lucha puede tener dos interpretaciones:

O bien, se trata de "la lucha cósmica entre las potencias del bien y el mal que se disputan la posesión del moribundo", asistiendo éste como un extraño; o bien, estamos ante la última prueba o tentación al moribundo arbitrada por Dios y su corte $^{64}$.

En este segundo caso:

El moribundo verá su vida entera tal como está contenida en el libro, y será tentado, bien por la desesperación de sus faltas, bien por

63 Ariès, Historia de la muerte... p. 48.

64 Ibidem, p. 48. 
la vanagloria de sus buenas acciones, bien por el amor apasionado de las cosas y los seres. Su actitud [...] borrará de golpe todos los pecados de su vida si rechaza la tentación o, por el contrario, anulará todas sus buenas acciones si cede a ella. La última prueba ha reemplazado el Juicio Final ${ }^{65}$.

El aterrorizado agonizante no puede cometer ninguna equivocación ni sucumbir a las postremas tentaciones que sobrelleva en completa soledad, ya que nadie en la habitación puede percibir lo que él está viendo, lo que está sucediendo. Como podemos intuir, en semejante circunstancia, aquellas necesidades que el moribundo debería cubrir, aquellas palabras hacia sus seres queridos que debería pronunciar, se ven abortadas ya que se encuentra demasiado aterrado ante la repercusión y trascendencia de su última decisión y ante la visión de semejante espectáculo.

La muerte como espera apacible y despreocupada de la llegada del Juicio Final gracias al bautismo queda relegada al olvido. Por esa razón, el diablo —en su primera tentación recogida en el capítulo primero del Ars — procura engañar al moribundo con la tranquilidad que proporcionaría tanto la inexistencia del infierno como la salvación indiscriminada para todos los creyentes:

Esta fe e creencia que tú tienes, non es como tú la crees o segund que la predican, ni ay infierno alguno: todos avemos de ser salvos (Cap. I).

El debate judicial sobre su propia salvación o condenación, al que asiste el moribundo como imputado y testigo pasivo y silencioso, se desarrolla a través de cinco turnos de acusación por parte del diablo y cinco de defensa por parte del ángel guardián. En sus manos está la decisión de inclinarse hacia uno u otro, lo que provoca que toda su existencia se ponga en juego en el último instante. Paradójicamente, el moribundo puede arrepentirse, obteniendo así el perdón de Dios y la salvación eterna independientemente de la trayectoria de toda una vida de pecado, o sucumbir a la última tentación y condenarse, a pesar de haber vivido de forma intachable. Esta simplificación perversa, que constituye el examen decisivo en el preciso instante de la muerte, impelía al creyente a seguir las enseñanzas expuestas en el arte de bien morir ${ }^{66}$.

A través de unos ritos aprendidos, el moribundo salvaría su alma con independencia del comportamiento que le hubiera caracterizado a largo de su vida, siempre 
y cuando cumpliera los requisitos al pie de la letra ${ }^{67}$. Dicha ritualidad caracteriza y configura la religiosidad extrínseca que el Ars moriendi difunde. No importa si el moribundo intentó vivir de acuerdo a las enseñanzas evangélicas; lo que importa es usar la religión y sus fórmulas, sus oraciones y sus ritos para lograr la salvación del alma, tal y como caracteriza a la superstición o a la religiosidad extrínseca.

En un principio, el Ars moriendi reconfortaría a quienes buscaran la seguridad de un ritual, de un extenso recuento cuantitativo de oraciones y gestos con los que parecer arrepentido ${ }^{68}$; sin embargo, al final, quienes buscaran este tipo de seguridad nunca tendrán la certeza de que fuese cuantitativamente suficientes $\mathrm{y}$, por tanto, lejos de apaciguarles, les induciría una angustia mayor.

Como ejemplo de esta religiosidad extrínseca, encontramos en el capítulo XI el siguiente texto:

[...] diga tres vegadas este verso: Dirupisti, Domine, vincula mea, tibi sacrificabo hostiam laudis; porque este verso, segund Cassiodoro, se cree que es de tanta virtud que los pecados de los ombres sean remitidos, si en fin estando en verdadera confessión es dicho. Item, diga tres vegadas estas palabra o otras semejantes: "La paz de Nuestro Señor Ihesu Cristo e la virtud de la su Passión e la señal de la Santa Cruz e la integridad de la Señora virgen Santa María e la bendición de todos los santos e santas, la guarda de los ángeles e las ayudas de todos los escogidos sean entre mí e entre todos los mis enemigos, visibles e non visibles en esta hora de la mi muerte. Amén". Finalmente diga: "En las tus manos, Señor, encomiendo el mi spíritu" (Cap. XI).

Ante las repeticiones expresadas tres veces y en voz alta, Bayard se pregunta si no estaremos más bien ante un conjuro que ante una oración ${ }^{69}$.

Como indican González, Saquero y Caerols, "si el hombre logra seguir la guía que esta obra le señala, es decir, si aprende a morir cristianamente, hará que triunfen los intercesores celestiales sobre los demonios y ello supondrá [...] su buena muerte" 70 . Sin embargo, este tipo de religiosidad extrínseca que configura el Ars moriendi le aleja de tal posibilidad, ya que, como hemos dicho, aumenta su ansiedad en el momento de morir. El practicante de dicha religiosidad busca saber qué tiene que hacer y cuántas veces, encaminándose hacia una vorágine de gestos que constantemente le harán dudar sobre la suficiencia de su número.

67 Rebeca Sanmartín Bastida, "Desarmando el rostro de la muerte: El ritual alegórico del Ars moriendi”, en Iberoromania, no 60 (2004), p. 45.

68 Ibídem, pp. 47 y 57.

69 Bayard, L'art du bien mourir..., p. 118.

70 González Rolán, et al., Ars moriendi..., p. 45. 
No hay que olvidar, que el creyente persigue "sauver son âme et donc mourir en l'Église, car hors d'elle il n'y a point de salut. Les cultes non chrétiens et toutes pratiques non recommandées par le clergé ne mènent qu'à la damnation" ". Por tanto, el moribundo se veía forzado a practicar una religiosidad que no calmaría sus angustias ni necesidades en detrimento de otra religiosidad más interiorizada o de un gobierno autónomo y personal del final de su vida.

\subsection{Influencia en el entorno de moribundo}

Para Jean Gerson, autor del arquetipo que dio lugar a las dos versiones latinas del manual, lo más importante era lograr que el alma viviera para siempre; por tanto, no sólo el agonizante debía cumplir una serie prescripciones para lograrlo, sino que también quien estuviera junto al lecho de muerte debía leerle historias y oraciones para la obtención de este propósito ${ }^{72}$. Así lo describe Lawrence:

[...] no debían dejarlo en paz ni un solo instante; cantando salmos en alta voz para silenciar cualquier palabra involuntaria de insumisión y sujetándolo crudamente para que no diera coces, acosaban al infeliz con un chorro ininterrumpido de preguntas e interrogaciones devotas ${ }^{73}$.

Para este menester, el Ars moriendi recomienda la presencia de un compañero adecuado, fiel y devoto, un laico perteneciente a una de las múltiples cofradías creadas por los mendicantes, recomendación quizás debida a la escasez de sacerdotes por los distintos brotes de peste negra. Sin embargo, en lo que respecta a los familiares más allegados, su mujer, sus hijos, sus parientes y amigos más íntimos, se prohíbe terminantemente que se acerquen a la cabecera del lecho en pro de salvaguardar la salud espiritual del moribundo ${ }^{74}$.

Para justificar la exclusión de familiares y amigos alrededor del lecho, encontramos dos textos. El primero pertenece a la traducción castellana del arquetipo de las dos redacciones latinas del Ars moriendi: De scientia mortis de Jean Gerson y el segundo al capítulo $\mathrm{V}$ del Ars moriendi en el que aparece la predisposición en contra de dicha presencia al hablarnos sobre el injusto padecimiento que sufre el moribundo:

En ninguna manera le pongan delante al enfermo, si es posible, amigos mundano, ni mujer, ni hijos, ni bienes de fortuna, ni le

71 Bayard, L'art du bien mourir..., p. 77.

72 González Rolán, et al., Ars moriendi..., p. 23.

73 Ibidem, p. 12.

74 Ibidem, p. 45. 
traygan a la memoria cosa d'éstas, sino ya que aprovechasse para la salud espiritual d'él, o si por alguna otra justa causa no se pudiesse escusar $^{75}$.

[...] lo que mucho te redobla e agravia tu dolor, es que ninguno ha compassión de ti. Lo qual, por cierto, non es dubda que sea contra toda razón, ca aunque tus amigos e parientes de palabra muestren que han compassión de ti, en la verdad ellos dessean tu muerte por los bienes que tú has de dexar, los quales esperan de heredar; porque es cosa clara que salida tu ánima del cuerpo, apenas lo querrán tener por sólo un día en casa (Cap. V).

Según Florence Bayard, el citado capítulo V puede estar haciéndose eco del miedo al abandono que sufrían aquellos moribundos cuya realidad estaba marcada por los enterramientos sin ritos funerarios causados por la peste negra y otras enfermedades ${ }^{76}$. Sin embargo, el autor considera que también puede reflejar la voluntad del clero de excluir a familiares y amigos para controlar "les rites lä̈cs, car la famille confraternelle s'avère être un bon moyen d'encadrement". Bayard se pregunta si la exclusión de los más allegados, no perseguiría sustituir esta presencia laica alrededor del lecho por otra más clerical, así como promover el papel del notario, sobre todo del prêtre-notaire, para recoger las últimas voluntades y disposiciones testamentarias ${ }^{77}$.

La importancia del testamento, que conocerá un auge a partir del siglo XII llegando a su plenitud entre los siglos XIII y XV, trajo consigo la proliferación de los clérigos como notarios en las cabeceras del lecho de los moribundos. Esto provocó un vínculo casi automático entre testamento y confesión, entre intestado y déconfes ${ }^{78}$. El moribundo corría el riesgo de no ser enterrado cristianamente si no dejaba hecho testamento, convirtiéndose éste en un segundo viático ${ }^{79}$.

Según Bayard, el Ars moriendi, que instaba a testar, únicamente permitía el recordar o traer a la memoria del moribundo sus bienes temporales siempre y cuando se persiguiera la salvación de su alma a través del testamento y de una muerte cristiana ${ }^{80}$ :

Donde es de notar singularmente, que mucho se debe guardar que, a alguno stante en el artículo de la muerte non sean reduzidos a la

75 Ibidem, p. 165.

76 Bayard, L'art du bien mourir..., p. 110.

77 Ibídem, p. 111.

78 Muerto sin confesión. Cécile Treffort et Pierre Guinard, À réveiller les morts: la mort au quotidien dans l,Occident médiéval. Lyon: Presses universitaires de Lyon, 1993, p. 146.

79 Bayard, L'art du bien mourir..., p. 121.

80 Ibídem, p. 121. 
memoria la muger, fijos, amigos corporales e otros bienes temporales, salvo en quanto requiere aquello la salud espiritual d' él, porque sería en otra manera muy peligroso, por quanto por ellos se distraería e apartaría de aquellas cosas que son de la salud de su ánima, en las quales dexadas todas otras cosas, entonces mayormente debe ser atento e ocupado con todas sus fuerças interiorese exteriores, non en las cosas miserables temporales e carnales, en las quales pensar e entender en tal tiempo sería muy peligroso. De manera que un ombre que solo por el buen arrepentimiento e propósito justo que en aquel tiempo uviesse se pordría salva, dexaría de alcançar la salvación e iría a condempnación, teniendo el coraçón e su querer e desseo en los bienes temporales (Cap. IX).

La Iglesia añadirá cláusulas piadosas a las profanas ya existentes en busca de un mayor control, sumando a las invocaciones, a la elección del lugar de sepultura y a las ceremonias, conmemoraciones y donaciones caritativas la designación de los herederos y de los legados a parientes y amigos ${ }^{81}$. En aras de favorecer el control eclesial, el Ars moriendi apela a las falsas intenciones de los familiares que no dejan al confesor o al compañero devoto acercarse al lecho en previsión de cambios en el testamento:

Porque comunmente aun los enfermos non piensan de morir, e por quanto el marido o la muger restante, e los fijos e parientes que entienden de heredar sus bienes, más procuran a lo induzir a su amor, llorándolo por que les dexe más bienes. E lo que peor es aun non dexan entrar a personas devotas que los confortarían, por recelo que les fagan mudar el testamento o mandas. E assí, muchas vezes, las ánimas de los morientes miserablemente se peligran (Cap. XI).

Conviene recordar que las órdenes mendicantes, confesores populares apreciados por sus oficios fúnebres, eran quienes principalmente redactaban los testamentos como notarios. Su éxito se debía no sólo al recelo que despertaban los "ecclésiastiques pressants et menaçants qui incitaient par tous les moyens, dont la peur, à ne pas oublier l'Eglise dans les testaments" ${ }^{\text {"2 }}$; sino también al privilegio papal por el que se otorgaba a las órdenes mendicantes el derecho de escuchar en confesión, dar la absolución y enterrar a los muertos. De este modo se ganaron rápidamente la preferencia de los moribundos, siendo muy demandados tanto sus cementerios 
como sus iglesias ${ }^{83}$. En cualquier caso, la presencia del mendicante o del ecclésiastique pressant e manaçant quedaba garantizada.

Tras superar las cinco tentaciones y disponerse a morir encomendándose a Dios, el Ars moriendi propone la repetición por parte de los presentes de una serie de oraciones en el caso de que el moribundo las desconozca:

Mas si el enfermo non supiere las oraciones, diga alguno de los que están presentes, a alta boz ante él, algunas oraciones o historias devotas en las quales seyendo sano él tenía devoción.

$[\ldots]$

Donde debemos notar, que pues la salud del ombre stá e consiste en su fin, que cada uno debe con grand diligencia e cuidado proveer de algund amigo o compañero devoto, idóneo e fiel, el qual le sea e esté presente en su fin e muerte, para que le conseje e conforte en la constancia de la fe, e lo incite e provoque a aver paciencia e devoción, confiança e caridad e perseverança e todas buenas obras, dándole esfuerço e animando en la agonía e batalla final, e diciendo por él algunas devotas oraciones (Cap. XI).

Para Bayard ${ }^{84}$, el modo de predicación itinerante de las órdenes mendicantes y el nuevo público urbano al que atendían alimentaron la aparición del Ars moriendi, cuya paternidad se atribuye también, según diferentes hipótesis, a dominicos y franciscanos. Dicha Ars resultaba manejable y fácil de utilizar para el más simple de los miembros de la orden como asimilable para el vulgo a la que iba dirigida. Los predicadores de las órdenes mendicantes rara vez evocan la muerte colectiva ya que, junto a los grandes sermones, surge la necesidad de una mayor intimidad con el feligrés.

La presencia de dichas órdenes dentro de las poblaciones, les permite observar los comportamientos y promover cultos o creencias que estuvieran surgiendo. Por ello, la emergente religión de las obras que difunden va acompaña de numerosas prácticas y formulas para los feligreses que cubren sus necesidades con algunas "recettes simples qui peuvent chasser les démons du lit de mort" 85 ; aún a riesgo, como señala Bayard, de provocar las críticas por mantener y alimentar las supersticiones. Por tanto, el Ars moriendi responde bien a los intereses de la población ya que conjuga una devoción tanto cristiana como mágica pues permite el uso del Ars como talismán ${ }^{86}$ lo que ratifica el carácter supersticioso de la religiosidad extrínseca que promulga. 


\section{ANÁLISIS Y CONSECUENCIAS}

A finales del siglo XIV, la muerte aparece de pronto en todo su horror. Aquella muerte domada y amable de Ariès, aquella muerte "aceptada, esperada o sufrida casi con gozo" da paso a otra temida y odiada, a un sentimiento nuevo tanto de la conciencia individual como de la conciencia de la propia muerte. Se abandona el destino común inevitable para asumir un final personal terrorífico ${ }^{87}$.

Este hombre medieval, que no cuestionaba su creencia en Dios y en Satanás y que sufría la angustia de que éste último pudiera manifestarse ante él en algún momento de su vida ${ }^{88}$, ahora, en las postrimerías de la misma, se encuentra rodeado de demonios y ángeles al asistir a la batalla final entre las fuerzas del bien y del mal como testigo y como juez de su propio destino ${ }^{89}$. Esta capacidad extrasensorial del hombre de ver las fuerzas celestiales e infernales en el momento de su agonía fue posiblemente un tema recurrente en las predicaciones de los clérigos en general y de las órdenes mendicantes en particular ${ }^{90}$. Acertadamente Rebeca Sanmartín Bastida ${ }^{91}$ señala que el moribundo se enfrenta a su muerte muy solo y muy acompañado al mismo tiempo ya que no está rodeado de las personas que le quieren, con quienes ha compartido alegrías y penas a lo largo de la vida, sino de fuerzas del bien y del mal pertenecientes al más alláa' .

La mayoría de las necesidades y esperanzas, que el moribundo precisa cubrir — como vimos en la primera parte- están relacionadas directa o indirectamente con la presencia a su alrededor de familiares y seres queridos; sin embargo, todos ellos han sido excluidos de la escena y sustituidos por una gran concentración de seres sobrenaturales y, en representación de la Iglesia, un compañero adecuado, fiel y devoto. Este último, en lugar de atender las necesidades y esperanzas del moribundo, debe recitar oraciones y cantar salmos en voz alta, silenciando sus quejas, prestando oídos sordos a su sufrimiento y estigmatizando sus manifestaciones externas. Según el manual, dichas manifestaciones y quejas son muestras del poco amor que se tiene a Dios:

[...] segund testigua Jherónimo, que dize así: "Si alguno padesce o rescibe la muerte o enfermedad con dolor e impaciencia e pesar, señal es que non ame a Dios segund debe". E Sant Paulo dize que: "La caridad es paciente e benigna" ${ }^{33}$, e aquel que non se conforma

87 González Rolán, et al., Ars moriendi..., p. 20.

88 Le Goff 1999, p. 138-139.

89 González Rolán, et al., Ars moriendi..., p. 41.

90 Ibidem, p. 43.

91 Rebeca Sanmartín Bastida, El arte de morir. La puesta en escena de la muerte en un tratado del siglo XV. Madrid: Iberoamericana, 2006, p. 194.

92 González Rolán, et al., Ars moriendi..., p. 59.

931 Corintios 13: 4. 
con la voluntad divina en su fin e muerte, plaziéndole de su fin e de ir para Nuestro Señor con gran arrepentimiento de sus pecados e con propósito de emendar su vida si Dios lo permitiesse más vivir, es de creer que non va buen camino (Cap. V).

La necesidad de verse rodeado de los seres queridos y, por tanto, solucionar cuestiones prácticas y participar en expresiones afectivas que satisfagan the five things no están bien vistas en el Ars moriendi según indicaban los capítulo V, IX y X.

Tanto el reemplazo de los familiares y amigos por un miembro del clero, o amigo devoto, como la sustitución de la expresión de las necesidades y esperanzas del moribundo por la profesión de fe y de sus artículos garantizan el alejamiento de una buena muerte. Ni siquiera la cuarta amonestación del proemio ${ }^{94}$ que incumbe a los allegados se lleva a cabo en presencia de éstos. Además, el chantaje que supone el cumplimiento de dichas cinco directrices para poder formar parte del número de los salvados hace que el moribundo centre su atención en preocupaciones de menor relevancia para él durante los breves instantes de vida que le quedan, ya que le obligan a desatender aquéllas que realmente necesita cubrir.

La buena muerte, que perseguía el Ars moriendi, no se vislumbra como tal si las necesidades y esperanzas del moribundo quedaban cercenadas por el cumplimiento de fórmulas, oraciones y gestos que presuntamente garantizaban la salvación de su alma pero que al mismo tiempo acrecentaban su ansiedad. Dicha ansiedad, tan inconveniente a la hora de experimentar una buena muerte, queda garantizada con la vivencia de las cinco sucesivas tentaciones demoníacas no experimentadas con anterioridad:

E es de saber, que en el artículo de la muerte los que han de morir han mayores e más graves temptaciones del enemigo que jamás ante uvieron (Prohemio).

Así mismo, el estado ansioso se afianza con la imposibilidad de alcanzar una buena muerte si no es a través de los contenidos del Ars moriendi, como indica el proemio, o a través de la creencia en los mandamientos de la Iglesia, como recoge el capítulo segundo:

[...] muy necessaria cosa es que provea e remedie el ombre a su ánima, por que non sea condempnada para siempre jamás. Para lo qual muy expediente e conveniente cosa es que qualquier que desea ser salvo, muchas vezes e con diligencia aya ante los ojos la Arte de bien morir, de la qual es la presente intención (Prohemio). 
[...] deves como varón resistir al diablo e firmemente creer todos los mandamientos de la Iglesia; ca la Santa Madre Iglesia non puede errar, como sea regida de Spíritu Santo (Cap. II).

Con respecto a los temores experimentados por el moribundo durante las tentaciones del diablo, destaco aquellos generados por la segunda tentación, la tentación por desesperación del capítulo tercero. Según el Ars moriendi, el diablo mostrará al moribundo aquellos pecados de los que no se haya confesado, pecados imposibles de perdonar tanto por su gravedad como por su número. La recopilación mental de dichos pecados por parte del moribundo junto al temor a un posible olvido u omisión de alguno de ellos aumentaría su ansiedad y turbaría su mente, independientemente del remedio aportado en el capítulo cuarto. Sin embargo, la inspiración del ángel en dicho capítulo recalca el poder de la contrición para lograr el perdón de los pecados con independencia de la confesión auricular:

$¡ \mathrm{O}$ ombre, por qué deseperas! Aunque tantos robos e furtos e homicidios uviesses cometido quantas arenas e gotas ay en el mar, e aunque tú solo uviesses cometido todos los pecados del mundo todo, e non uviesses fecho d'ellos penitencia ni confessión, ni uviesses agora facultad e espacio para confessarlos, ni por eso deves desesperar, porque ental caso la contrición sólo de dentro, sin alguna vocal confessión vasta (Cap. IV).

En este punto resulta relevante incluir la comparación que Tomás González, Pilar Saquero y José Joaquín Caerols establecen entre las Coplas de Jorge Manrique y las Artes moriendi ${ }^{95}$. Su comparación muestra dos vivencias contrarias y contemporáneas.

Según relatan las Coplas ${ }^{96}$, don Rodrigo Manrique muere plenamente consciente, tras encomendar su alma a Dios, acompañado y rodeado de "toda su familia, mujer, hijos, hermanos e, incluso, criados", como indicaba la estrofa XL (vv. 469-480), y sin la visión de las fuerzas extrasensoriales. Su final parece reflejar la muerte tradicional en la que el yacente, resignado y presto a aceptar su muerte, se despedía del mundo encomendándose a Dios con una plegaria final: commendatio animae ${ }^{97}$. Como seńala Ariès, en la commendatio animae hay dos ausencias importantes; ya que no se habla de la extremaunción, reservada a clérigos, ni hay invocación alguna dirigida a la Virgen María ${ }^{98}$.

95 González Rolán, et al., Ars moriendi..., p. 60.

96 De ahora en adelante cito por la edición de Manrique, Jorge (1993), Poesía, ed. Vicente Beltrán, Barcelona, Crítica.

97 González Rolán, et al., Ars moriendi..., p. 60.

98 Philippe Ariès, El hombre ante la muerte. Madrid: Taurus, 2011, p. 29. 
Por el contrario, en el Ars moriendi, recomienda que el moribundo invoque primero a Dios, luego a la Virgen María como abogada y mediadora, después a los ángeles, santos, mártires, confesores y vírgenes, para, posteriormente, recitar tres veces dos frases muy explícitas y concluir encomendándose a Dios (Cap. XI). Además, el moribundo debe recibir con gran reverencia y devoción, no sólo la extremaunción, sino todos aquellos sacramentos que sean necesarios para la salvación de su alma (Prohemio) en ausencia de seres queridos.

La religiosidad extrínseca que aquí se describe aumenta el grado de ansiedad del moribundo apartándole de una buena muerte. Así mismo, mientras que en el primer caso se garantizaba que las necesidades y esperanzas de don Rodrigo quedaran cubierta por la presencia de los familiares y por la actitud, consciencia y control ejercido por el agonizante; en el segundo, toda invocación a las innumerables fuerzas celestiales parece insuficiente, en un entorno carente de allegados y con la imposibilidad de que sus necesidades queden atendidas debido al rezo constante de oraciones en voz alta de personas ajenas a su entorno que silencian sus manifestaciones verbales o no verbales. La pérdida de protagonismo y de control ante su propia muerte queda garantizada. Ambos ejemplos muestran, respectivamente, las características básicas de una buena muerte y de una mala muerte.

\section{Conclusiones}

Nada tranquiliza tanto — cuando el agonizante es consciente de que vamos a morir - como el diálogo confiado y abierto con los seres queridos; y nada agrava tanto el dolor y la ansiedad como la soledad, la sensación de abandono y la imposibilidad de dialogar con las personas amadas. Por tanto, vivir el momento de la muerte flanqueados por seres sobrenaturales, temiendo y teniendo que decidir a una sola carta la vida futura sin posibilidad de incurrir en errores, tenía que resultar aterrador y angustioso para aquellos que creyeran en la veracidad de este juicio pre mortem. Tampoco hay que olvidar la soledad del momento en sí, tanto por la ausencia de seres queridos como por la presencia substitutiva de representantes de la Iglesia incapaces de advertir la presencia de fuerzas extrasensoriales a las que tenía que enfrentarse el moribundo.

El uso del habla en esos últimos instantes que debería utilizarse para cubrir las necesidades y las esperanzas que brotan espontáneamente en las postrimerías de la vida, tenía que emplearse en solventar dilemas de segundo orden que el miedo y la ansiedad —inoculados por la Iglesia — había convertido en conflictos de primer orden. Aquellas palabras que había de dirigir a los allegados quedaban sin ser dichas y aquellas otras que necesitaba escuchar, quedaban sin ser oídas. A su vez, los rituales propuestos por el Ars moriendi incrementaban el grado de ansiedad a través de la distanasia religiosa que emana de la religiosidad extrínseca que la Iglesia institucional del siglo XV promovía conscientemente. 
Por tanto, según se explicaba en la primera parte de este artículo, todo aquello que no lleve a la consecución y la satisfacción de las necesidades, anhelos y esperanzas allí descritas supone un desplazamiento en dirección contraria a la obtención de una buena muerte. Así mismo, todo aquello que aumente el grado de ansiedad y de incertidumbre del moribundo, le aleja objetivamente de la posibilidad de alcanzar dicho propósito. 